\title{
Development and Psychometric Evaluation of Coronary Artery Disease Treatment Adherence Scale
}

\author{
Nahid Dehghan Nayeri · Mohammad Ali Yadegary
}

Khatereh Seylani · Elham Navab

Received: October 11, 2018 / Published online: April 10, 2019

(C) The Author(s) 2019

\begin{abstract}
Introduction: Poor treatment adherence reduces treatment effectiveness and increases healthcare costs. The promotion of treatment adherence necessitates valid and reliable tools to assess the effectiveness of adherence promotion strategies. This study was undertaken to develop and evaluate the psychometric properties of the Coronary Artery Disease Treatment Adherence Scale.

Methods: This methodological study was conducted in two phases. In the first phase, a literature review was done and a 62-item scale was developed. In the second phase, different methods were used to assess the psychometric properties of the scale, namely its face validity,
\end{abstract}

Enhanced digital features To view enhanced digital features for this article go to https://doi.org/10.6084/ m9.figshare.7925000.

Electronic supplementary material The online version of this article (https://doi.org/10.1007/s40119019-0135-4) contains supplementary material, which is available to authorized users.

N. Dehghan Nayeri

Nursing Management Department, Nursing and Midwifery Care Research Center, Tehran University of Medical Sciences, Tehran, Iran

M. A. Yadegary $(\bowtie) \cdot$ K. Seylani · E. Navab Critical Care Nursing Department, School of Nursing and Midwifery, Tehran University of Medical Sciences, Tehran, Iran

e-mail: ma.yadegary@gmail.com content validity, construct validity, internal consistency, and test-retest stability.

Results: During face and content validity assessments, the number of items was reduced from 62 to 53. Moreover, in construct validity assessment via exploratory factor analysis, 18 items were deleted because their factor loading values were less than 0.3 . The remaining 35 items were loaded on four factors, namely medication adherence, dietary adherence, exercise adherence, and healthy lifestyle adherence. The Cronbach's alpha values of the scale before and after factor analysis were 0.850 and 0.862 , respectively. Its test-retest intraclass correlation coefficient was also 0.85 .

Conclusions: The Coronary Artery Disease Treatment Adherence Scale is a valid and reliable tool and can be used in different healthcare settings for the assessment of treatment adherence among patients' with coronary artery disease.

Trial Registration: Tehran University of Medical Sciences, identifier, 35456.

Keywords: Coronary artery disease; Psychometrics; Review of literature; Treatment adherence

\section{INTRODUCTION}

Coronary artery disease (CAD) is the first leading cause of death [1] with 17.5 million cases in 
the world [2, 3] CAD mortality rate in the world and in developing countries is $25 \%$ and $32 \%$, respectively [4]. Around $80 \%$ of CAD-induced deaths happen in low- and moderate-income countries [1]. CAD is also the first leading cause of death in Iran with a mortality rate of $39.3 \%$ [2].

There are different treatments for CAD, including pharmacological treatments, percutaneous coronary intervention, and coronary artery bypass surgery. However, these treatment modalities do not stop the processes of atherosclerosis and coronary artery stenosis $[5,6]$. A study showed that in a 2-year follow-up period after coronary angioplasty, 30 to $40 \%$ of patients experienced recurrent angina, myocardial infarction, another angioplasty, or death [7].

The most significant factor behind treatment success is the patients' adherence to treatments [8]. The World Health Organization Adherence Meeting in June 2001 defined adherence as "the extent to which the patient follows medical instructions" [9]. Treatment adherence can reduce CAD mortality rate by $11 \%$. Contrarily, poor treatment adherence among CAD patients significantly increases mortality rate, rehospitalization rate, and healthcare costs [8]. Estimates show that in the United States of America, treatment non-adherence causes 125,000 cases of death annually and accounts for $33-69 \%$ of re-hospitalizations [10]. The World Health Organization reported that longterm treatment adherence among patients with chronic diseases is 50\%. This rate is much lower in developing countries [9]. Another study showed that $13-60 \%$ of patients with myocardial infarction do not adhere to their treatments [11].

Assessment of treatment adherence is essential for planning treatments, ensuring their effectiveness, and deciding on future treatments. Such an assessment requires valid and reliable tools. However, there is no gold standard tool for adherence assessment and thus previous studies used different methods for the assessment [9]. The most commonly used adherence assessment tool is the Morisky Medication Adherence Scale [12]. This scale was developed by Morisky et al. in 1986 and translated into Persian by Negarandeh et al. [13]. Despite its popularity, this scale solely assesses adherence to medications and does not address other components of treatment adherence. Some studies on CAD patients also used researcher-made adherence assessment tools, which had been used without providing any reliable data on their development and psychometric evaluation. Other adherence assessment tools also have obvious shortcomings, such as variant scales for subscale scoring, which cause difficulties in answering items, analyzing and interpreting the collected data, and comparing subscale scores $[14,15]$. Therefore, there is a great need for valid and reliable comprehensive tools for adherence assessment [16-18]. This study was undertaken to develop and evaluate the psychometric properties of the Coronary Artery Disease Treatment Adherence Scale (CADTAS).

\section{METHODS}

This article resulted from a PhD dissertation in Nursing approved by Tehran University of Medical Sciences, identifier, 35456.

The study was conducted in two phases. In the first phase, scale development is carried out and in the second stage; judgment/quantification on scale items is performed (psychometric evaluation) (Fig. 1).

\section{Phase 1. CADTAS Development}

The first phase in the scale development is to generate and obtain items relevant to the question and the targeted population [19]. There are three methods for the initial item generation that included deductive, inductive, and a combination of the two. Deductive methods involve item generation based on an extensive literature review and pre-existing scales [20]. The most widely source of qualitative data is the literature review that produces tests with effectively unlimited item banks $[19,21]$. An additional function of the literature review is to gain a more concrete understanding of the construct by identifying conceptual definitions of each dimension and relevant 


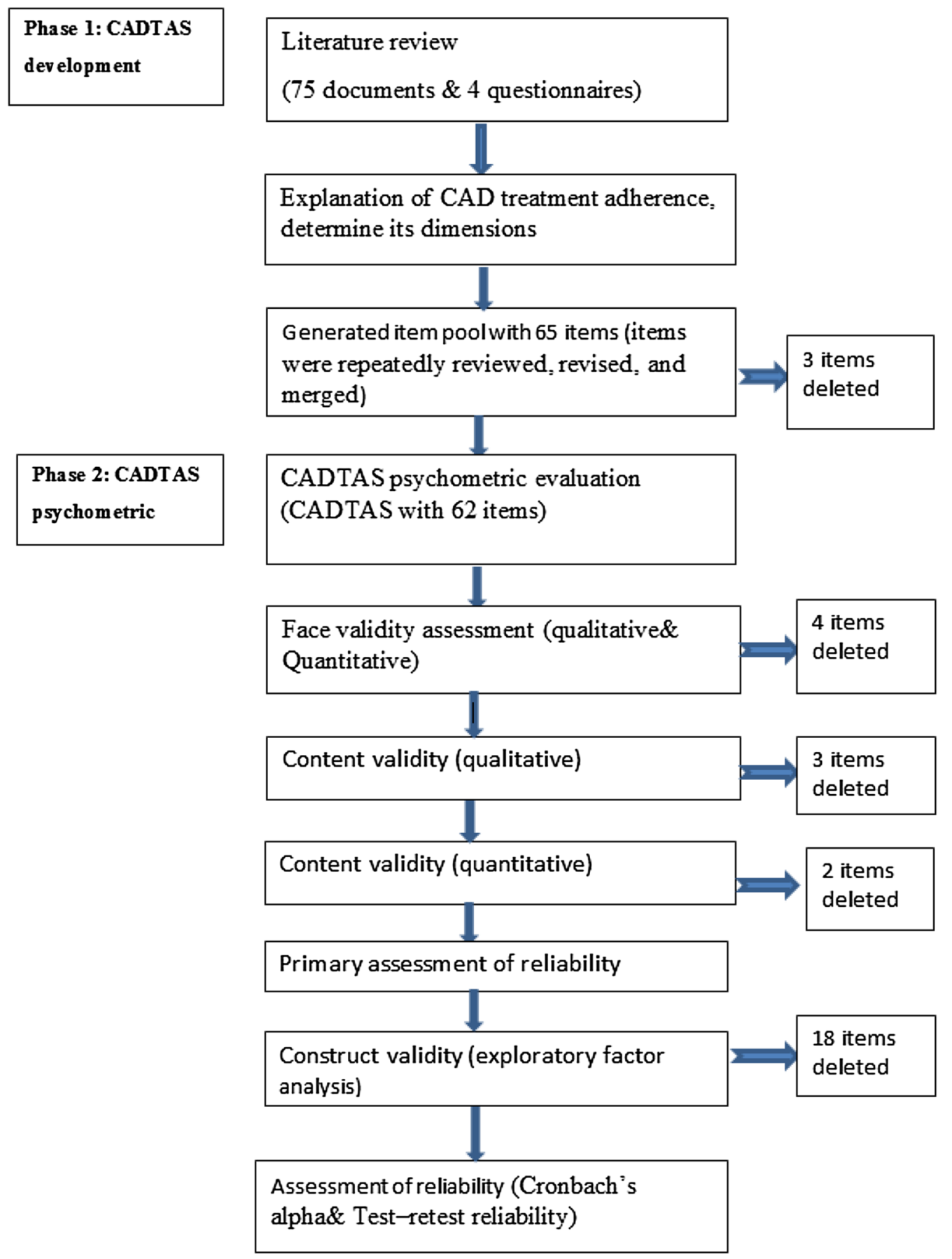

Fig. 1 Stage of development and psychometric evaluation of CADTAS

empirical items that describe each dimension [22].

CADTAS was developed deductively based on the existing literature. Accordingly, in order to determine the dimensions of treatment adherence and generate CADTAS items, we searched online databases such as ScienceDirect, Embase, MEDLINE, CINAHL, IranMedex, Magiran, and SID in order to retrieve adherencerelated studies. Search terms were treatment 
adherence, CAD, ischemic heart disease, coronary angioplasty, and coronary artery bypass surgery. Studies were included in the analysis if they were directly related to treatment adherence, were literature review or original study, and had been published in Persian or English after 2000. This search protocol yielded 706 documents. Irrelevant studies were excluded and 352 studies and four questionnaires were kept. Then, the full texts of all retrieved documents were read and 75 documents directly related to CAD treatment adherence were selected. These 75 documents were reviewed and summarized to define CAD treatment adherence, determine its dimensions, and then, generate CADTAS items. We also considered societies' recommendations for assessment of adherence.

After summarizing the documents, the concept of adherence to the treatment was explained and its dimensions were determined. We wrote the maximum possible items in each dimension.

Therefore, an item pool with 65 items was generated. The items were repeatedly reviewed, revised, and merged and finally, the primary CADTAS was generated with 62 items. Items were scored via a five-point Likert-type scale as follows: 1: "Never" (no treatment adherence); 2: "Rarely" (limited treatment adherence); 3: "Sometimes" (moderate treatment adherence); 4: "Often" (good treatment adherence); and 5: "Always" (strict treatment adherence). Higher scores represented closer treatment adherence. Some items were negatively worded in order to reduce the negative effects of haphazard responses to items.

\section{Phase 2: CADTAS Psychometric Evaluation}

In this phase, the validity and reliability of CADTAS were assessed. Validity assessment included the assessments of face, content, and constructs validity.

\section{Assessment of Face Validity}

Qualitative and quantitative methods were used for face validity assessment. In qualitative assessment of face validity, ten low-literacy CAD patients were randomly selected and interviewed face-to-face about the difficulty, appropriateness, and clarity of CADTAS items. Then, the items were revised to make them simpler and clearer.

Quantitative assessment of face validity was done via calculating impact score for each item. Ten randomly selected CAD patients rated the importance of each CADTAS item using a fivepoint rating scale as follows: 1 : Not important; 2: Slightly important: 3: Somehow important; 4: Important: and 5: Very important. Impact score for each item was calculated using the following formula, "Impact score = Frequency $(\%) \times$ Importance". "Frequency" in the formula was the number of patients rated the item 4 or 5 , while "Importance" was the mean score of the item on the 1-5 rating scale. Items were kept in CADTAS if they obtained an impact score of 1.5 or more [23, 24].

\section{Assessment of Content Validity}

Assessment of content validity was also performed via both qualitative and quantitative methods. In the qualitative method, ten experts in instrument development, cardiology, cardiac surgery, cardiac nursing, and treatment adherence evaluated and commented on the wording, essentiality, importance, appropriate placement, and scoring of the items. Then, items were revised using their comments. Quantitative assessment of content validity was performed by calculating content validity ratio (CVR) and content validity index (CVI). CVR was calculated to ensure that the most important and the most correct items had been selected for treatment adherence assessment. Accordingly, 14 experts in cardiology, cardiac surgery, and nursing evaluated the essentiality of the items via a three-point scale with the following three points: "Essential", "Useful but not essential", and Not essential". Then, the CVR of each item was calculated via the CVR formula, i.e., $\mathrm{CVR}=(\mathrm{Ne}-(\mathrm{N} / 2)) /(\mathrm{N} / 2)$, where $\mathrm{N}$ stands for the total number of experts and $\mathrm{Ne}$ stands for the total number of experts rated the intended item as essential. Lawshe noted that 
for 14 experts, items with CVR values of 0.51 and more are appropriate [25].

CVI was calculated to determine whether the items appropriately measure treatment adherence. The same 14 experts rated the simplicity, relevancy, or specificity, and clarity of each item on a four-point rating scale. Then, the number of experts rated an item 3 or 4 was divided by the total number of experts in order to calculate the CVI of that item. Items with a CVI of more than 0.79 were kept, while items with a CVI of 0.70-0.79 were revised and items with a CVI of less than 0.70 were removed. Finally, the average CVR and CVI were calculated for the whole CADTAS.

\section{Primary Assessment of Reliability}

After the assessments of face and content validity and before the assessment of construct validity, the reliability of CADTAS was assessed through the internal consistency method. Accordingly, Cronbach's alpha of the scale was calculated using the data collected from $30 \mathrm{CAD}$ patients. The minimum acceptable Cronbach's alpha was considered to be 0.70 [26].

\section{Assessment of Construct Validity}

Construct validity can be assessed with the use of exploratory factor analysis (EFA), confirmatory factor analysis (CFA), or with convergent, discriminant, predictive/ nomological, criterion, internal, and external validity. The group of extraction and rotation techniques to identify latent constructs is referred to as common factor analysis or exploratory factor analysis $[20,22]$.

As CADTAS was a new tool and we had no assumption about its dimensions, assessment of its construct validity was performed using exploratory factor analysis. The number of necessary individuals for factor analysis is $5-10$ individuals per item [27]. Therefore, we recruited six CAD patients per CADTAS item. Inclusion criteria were a definite diagnosis of CAD via coronary angiography, an age of 18 or higher, and receiving CAD treatments for at least 2 months. In order to select a sample of maximum variation, patients were recruited from three teaching hospitals and four clinics in Zanjan, Iran. Sampling was done conveniently. Recruited patients individually completed CADTAS. The data were entered into the SPSS software (v. 24) for factor analysis. Initially, the Kaiser-Meyer-Olkin (KMO) test was run to ensure the adequacy of the selected sample. $\mathrm{KMO}$ test value can range from 0 to 1 -the higher the test value, the more accurate the factor analysis. The minimum acceptable value is 0.70. Besides, Bartlett's test of sphericity was run to determine factor analysis suitability by testing whether the correlations among CADTAS items were strong enough so that the items could be clustered and also by testing whether the correlation matrix was significantly different from zero value.

Factor extraction in factor analysis was done via the principal component analysis method. The results of this method are presented as a matrix of each factor loading on each item. In fact, factor loading represents the correlation of an item with a factor and is used to maintain an item in a factor or remove an item from a factor after factor rotation. There are different methods for determining the number of factors. In this study, the number of factors was determined based on the variance of each item, eigenvalue, and scree plot. Then, varimax rotation was used to simplify the factors and make them interpretable. Extracted factors were labeled based on the items loaded on them. The minimum factor loading for keeping an item in the allocated factor was 0.3.

\section{Assessment of Reliability}

The internal consistency and the test-retest stability methods were used for the assessment of reliability. Stability, also called test-retest reliability, is the degree to which scores on the same test are consistent over time. In other words, this type of reliability provides evidence that scores obtained on a test at one time (test) are the same or close to the same when the test is re-administered some other time (retest). The more similar the scores on the test over time, the more stable the test scores. A common, 
minimally accepted sample size for a correlational study is 30 participants. If the variables correlated have low reliabilities and validities, a bigger sample is necessary. The procedure for determining test-retest reliability is quite simple: after administrating the test to an appropriate group and passing some time- about 2 weeks or more- administer it again and calculate the correlation between two series of data $[28,29]$.

Accordingly, 30 randomly selected patients completed CADTAS. Collected data were used to calculate Cronbach's alpha. Minimum acceptable alpha value was 0.7 [30]. Two weeks later, the same 30 patients recompleted CADTAS. Then, intraclass correlation coefficient was calculated to assess stability.

\section{Compliance with Ethics Guidelines}

All procedures performed in studies involving human participants were in accordance with the Ethics Committee of the Tehran Faculty of Nursing and Midwifery with No: IR.TUMS.FNM.REC.1396.2689 and with the 1964 Helsinki Declaration and its later amendments or comparable ethical standards. Informed consent was obtained from all individual participants included in the study.

\section{RESULTS}

Our literature review revealed that the meaning of the adherence concept has changed over time. Initially, it solely meant following a physician's medical orders. Accordingly, patients were inactive and accountable for treatment failure. However, the concept of adherence is currently so comprehensive that it requires patients to get actively involved in treatments and self-care. In other words, treatment plans are not imposed on patients; rather, they are designed, implemented, and evaluated via patients' active involvement and patient-professional interactions. In this viewpoint, adherence is determined by different factors and is considered to be the responsibility of patients (who act), healthcare professionals (who facilitate action), and social context (in which the action is performed) [8, 31, 32]. Currently, adherence is considered as the extent to which patients' behaviors comply with healthcare professionals' recommendations and instructions. Our literature review revealed that treatment adherence among patients with CAD consists of the four dimensions of adherence to dietary regimen, adherence to healthy lifestyle, adherence to medication therapy, and adherence to physical activity.

\section{Item Generation}

After identifying the four dimensions of treatment adherence based on the existing literature, the primary item pool was generated with 65 items. Items were repeatedly revised and reduced to 62 .

\section{Psychometric Evaluation}

Qualitative assessment of face validity was done by four female and six male patients with primary and secondary educations. In quantitative assessment of face validity, four items were removed due to an item impact score of less than 1.5.

In qualitative assessment of content validity, changes were made to the items and three items were removed based on the comments of the ten experts. Moreover, in the quantitative assessment of content validity, two items with a CVR of less than 0.51 were deleted. All remaining 53 items had a CVI of more than 0.79. The average CVR and CVI of the whole scale were 0.886 and 0.977 . Table 1 shows the number of items deleted during the different steps of psychometric evaluation.

After confirming face and content validity, primary reliability assessment was performed via the internal consistency method. Cronbach's alpha of the 53-item CADTAS was equal to 0.85 .

Construct validity of CADTAS was assessed via factor analysis. We recruited 318 CAD patients (six CAD patients per CADTAS item). Table 2 shows demographics characteristics of CAD patients recruited in evaluating construct validity and primary reliability assessment. 
Table 1 Items deleted in different steps of psychometric evaluation

\begin{tabular}{lll}
\hline $\begin{array}{l}\text { Steps of psychometric } \\
\text { evaluation }\end{array}$ & $\begin{array}{l}\text { Number of } \\
\text { items } \\
\text { deleted }\end{array}$ & $\begin{array}{l}\text { Number of } \\
\text { remaining } \\
\text { items }\end{array}$ \\
\hline $\begin{array}{l}\text { Primary assessment } \\
\text { Quantitative face validity } \\
\text { assessment }\end{array}$ & 3 & 62 \\
$\begin{array}{l}\text { Qualitative content } \\
\text { validity assessment }\end{array}$ & 3 & 58 \\
$\begin{array}{l}\text { Quantitative content } \\
\text { validity assessment via } \\
\text { CVR }\end{array}$ & 2 & 55 \\
$\begin{array}{l}\text { Quantitative content } \\
\text { validity assessment via } \\
\text { CVI }\end{array}$ & 0 & 53 \\
$\begin{array}{l}\text { Construct validity } \\
\text { assessment via factor } \\
\text { analysis }\end{array}$ & 18 & 53 \\
\hline
\end{tabular}

KMO test value was 0.809 , indicating that the recruited sample of patients was adequate enough for factor analysis. Moreover, the significant results of Bartlett's test of sphericity showed strong correlations among items $\left(\chi^{2}=\right.$ 4527.762; $\mathrm{df}=528 ; P<0.001)$, implying the suitability of factor analysis.

Factor number was determined via scree plot, eigenvalue, and factor rotation. Visual assessment of scree plot showed that 3-5 factors can be considered for CADTAS (Fig. 1). Based on eigenvalues, 17 factors with eigenvalues greater than 1 were identified, which collectively explained $63.5 \%$ of the total variance. The 17-factor structure was tested using different factor rotations. Finally, based on scree plot, the characteristics of the items, and factor rotation, we decided on a four-factor structure, which accounted for $45 \%$ of the total variance of treatment adherence. This four-factor structure had the highest level of intra-factor homogeneity and consistency. The minimum acceptable factor loading was 0.3. In the fourfactor structure, 18 items had a factor loading of less than 0.3. These 18 items were deleted and
Table 2 Demographic and clinical characteristics of CAD patients recruited for evaluating construct validity, primary reliability of CADTAS

\begin{tabular}{|c|c|c|c|}
\hline Variables & & Frequency & $\%$ \\
\hline \multirow[t]{2}{*}{ Age } & $<50$ years old & 51 & 16 \\
\hline & $>50$ years old & 267 & 84 \\
\hline \multirow[t]{2}{*}{ Sex } & Male & 216 & 67.9 \\
\hline & Female & 102 & 32.1 \\
\hline \multirow[t]{4}{*}{ Level of education } & $\begin{array}{l}\text { Reading and } \\
\text { writing }\end{array}$ & 154 & 48.4 \\
\hline & Primary school & 116 & 36.5 \\
\hline & Secondary school & 28 & 8.8 \\
\hline & High school & 20 & 6.3 \\
\hline \multirow[t]{2}{*}{ Marital status } & Single & 5 & 1.6 \\
\hline & Married & 313 & 98.4 \\
\hline \multirow[t]{5}{*}{ Occupation } & Housewife & 101 & 31.8 \\
\hline & Laborer & 40 & 12.6 \\
\hline & Clerk & 33 & 10.4 \\
\hline & Self-employed & 90 & 28.3 \\
\hline & Retired & 54 & 17 \\
\hline \multirow{3}{*}{$\begin{array}{l}\text { Adequacy of } \\
\text { income }\end{array}$} & Weak & 40 & 12.5 \\
\hline & Average & 127 & 39.9 \\
\hline & Good & 151 & 47.5 \\
\hline \multirow{3}{*}{$\begin{array}{l}\text { Number of risk } \\
\text { factors }\end{array}$} & One & 170 & 53.5 \\
\hline & Two & 119 & 37.4 \\
\hline & Three and more & 29 & 9.3 \\
\hline \multirow[t]{3}{*}{$\begin{array}{l}\text { Duration of the } \\
\text { disease }\end{array}$} & $\begin{array}{l}\text { Six months to } 1 \\
\text { year }\end{array}$ & 16 & 5 \\
\hline & $1-2$ years & 263 & 83.7 \\
\hline & $\begin{array}{c}\text { Older than } 2 \\
\text { years old }\end{array}$ & 39 & 12.3 \\
\hline \multirow[t]{3}{*}{ Severity of CAD } & $\begin{array}{l}\text { SYNTAX Score } \\
\quad \leq 22\end{array}$ & 84 & 26.4 \\
\hline & $\begin{array}{l}\text { SYNTAX } \\
\quad \text { Score }=23-32\end{array}$ & 104 & 32.7 \\
\hline & $\begin{array}{l}\text { SYNTAX score } \\
\quad \geq 33\end{array}$ & 130 & 40.9 \\
\hline
\end{tabular}


Table 2 continued

\begin{tabular}{|c|c|c|c|}
\hline Variables & & Frequency & $\%$ \\
\hline \multirow{3}{*}{$\begin{array}{l}\text { Percent of ejection } \\
\text { fraction }\end{array}$} & $<35 \%$ & 101 & 31.8 \\
\hline & $35-49 \%$ & 119 & 37.4 \\
\hline & $>50$ & 98 & 30.8 \\
\hline \multirow{3}{*}{$\begin{array}{l}\text { Number of } \\
\text { medications }\end{array}$} & $<4$ & 98 & 30.8 \\
\hline & Apr & 157 & 49.3 \\
\hline & $>7$ & 65 & 19.9 \\
\hline \multirow[t]{3}{*}{ Type of treatment } & CABG & 100 & 31.5 \\
\hline & PCI & 154 & 48.4 \\
\hline & $\begin{array}{l}\text { Medication } \\
\text { follow-up }\end{array}$ & 64 & 20.1 \\
\hline
\end{tabular}

therefore, the number of items reduced from 53 to 35 . The four extracted factors were named based on their items and were compared with the four dimensions of treatment adherence which had been identified in the literature review. The four extracted factors included medication adherence (11 items), dietary adherence (13 items), exercise adherence (four items), and healthy lifestyle adherence (seven items). The five possible answers to CADTAS items were "Always" (scored 5), "Often" (scored 4), "Sometimes" (scored 3), "Rarely" (scored 2), and "Never" (scored 1).

The negative effects of haphazard responses are reduced through the negative wording of some items. The total CADTAS score is 35-175, with higher scores standing for closer treatment adherence among CAD patients.

Table 3 shows characteristics of CAD patients recruited for evaluating final reliability of CADTAS. Final reliability assessment indicated that the Cronbach's alpha values and the intraclass correlation coefficients of CADTAS and all its four factors were greater than 0.70 and 0.80 , respectively (Table 4 ).

\section{DISCUSSION}

This study aimed to develop and evaluate the psychometric properties of CADTAS. The final
Table 3 Demographic and clinical characteristics of CAD patients recruited for evaluating final reliability assessment of CADTAS

\begin{tabular}{|c|c|c|c|}
\hline Variables & & Frequency & $\%$ \\
\hline \multirow[t]{2}{*}{ Age } & $<50$ years old & 5 & 16.7 \\
\hline & $>50$ years old & 25 & 83.3 \\
\hline \multirow[t]{2}{*}{ Sex } & Men & 20 & 66.7 \\
\hline & Women & 10 & 33.3 \\
\hline \multirow[t]{4}{*}{ Level of education } & $\begin{array}{l}\text { Reading and } \\
\text { writing }\end{array}$ & 9 & 30 \\
\hline & Primary school & 16 & 53.3 \\
\hline & Secondary school & 3 & 10 \\
\hline & High school & 2 & 6.7 \\
\hline \multirow[t]{2}{*}{ Marital status } & Single & 0 & 0 \\
\hline & Married & 30 & 100 \\
\hline \multirow[t]{5}{*}{ Occupation } & Housewife & 9 & 30 \\
\hline & Laborer & 4 & 13.3 \\
\hline & Clerk & 5 & 16.7 \\
\hline & Self-employed & 3 & 10 \\
\hline & Retired & 9 & 30 \\
\hline \multirow{3}{*}{$\begin{array}{l}\text { Adequacy of } \\
\text { income }\end{array}$} & Weak & 4 & 13.3 \\
\hline & Average & 7 & 23.3 \\
\hline & Good & 19 & 63.3 \\
\hline \multirow{3}{*}{$\begin{array}{l}\text { Number of risk } \\
\text { factors }\end{array}$} & One & 9 & 30 \\
\hline & Two & 10 & 33.3 \\
\hline & Three and more & 11 & 36.7 \\
\hline \multirow[t]{3}{*}{$\begin{array}{l}\text { Duration of the } \\
\text { disease }\end{array}$} & $\begin{array}{l}\text { Six months to } 1 \\
\text { year }\end{array}$ & 2 & 6.7 \\
\hline & 1 to 2 years & 21 & 70 \\
\hline & $\begin{array}{c}\text { Older than } 2 \\
\text { years old }\end{array}$ & 7 & 23.3 \\
\hline \multirow[t]{3}{*}{ Severity of CAD } & $\begin{array}{l}\text { SYNTAX score } \\
\quad \leq 22\end{array}$ & 9 & 30 \\
\hline & $\begin{array}{l}\text { SYNTAX } \\
\quad \text { score }=23-32\end{array}$ & 14 & 46.7 \\
\hline & $\begin{array}{l}\text { SYNTAX score } \\
\quad \geq 33\end{array}$ & 7 & 23.3 \\
\hline
\end{tabular}


Table 3 continued

\begin{tabular}{|c|c|c|c|}
\hline Variables & & Frequency & $\%$ \\
\hline \multirow{3}{*}{$\begin{array}{l}\text { Percent of ejection } \\
\text { fraction }\end{array}$} & $<35 \%$ & 11 & 36.7 \\
\hline & $35-49 \%$ & 11 & 36.7 \\
\hline & $>50$ & 8 & 26.6 \\
\hline \multirow{3}{*}{$\begin{array}{l}\text { Number of } \\
\text { medications }\end{array}$} & $<4$ & 9 & 30 \\
\hline & April 7 & 11 & 36.7 \\
\hline & $>7$ & 19 & 33.3 \\
\hline \multirow[t]{3}{*}{ Type of treatment } & CABG & 17 & 56.6 \\
\hline & PCI & 11 & 36.7 \\
\hline & $\begin{array}{r}\text { Medication } \\
\text { follow-up }\end{array}$ & 2 & 6.6 \\
\hline
\end{tabular}

version of CADTAS has 35 items in four dimensions. CADTAS is completed in around 15 minutes via self-administration and hence, it is an almost simple tool for treatment adherence assessment in different settings, including hospitals, primary healthcare centers, clinics, rehabilitation centers, and home settings.

The findings of this study showed that CADTAS has acceptable face validity, content validity, construct validity, and reliability. It is a practical instrument for measuring patient adherence to treatment.

The first dimension, dietary adherence, is comprised 13 items. Diet has a fundamental role in development and prevention of cardiovascular disease (CVD). Although the traditional research focused on single nutrients or foods, recent studies of dietary patterns have allowed for reflection on both the complexity and the synergies of food and nutrient intake [33]. In an attempt to validate an instrument measuring dietary adherence, Huijbregts et al. [34], based on WHO international dietary guidelines, developed the Healthy Diet Indicator (HDI).

The second dimension was healthy lifestyle adherence, which comprises seven items. There is a positive correlation between modifiable risks factors such as smoking and the harmful use of alcohol with coronary heart disease. Existence of these items are very important because most patients with cardiovascular disease continue to smoke after acute myocardial infarction, exposing themselves to a 50.0\% increased risk of recurrent coronary events among nonsmokers [35].

The third dimension, medication adherence, consists of six items. The most popular scale applied for the assessment of adherence is the Morisky Medication Adherence Scales (MMAS-4 and MMAS-8). This dimension of CADTS has a good Cronbach's alpha value (0.855), the same as the Morisky Medication Adherence Scale (0.83). MMAS against the CADTAS not allow to comprehensive assessment of adherence behaviors. Consequently limit developing interventions to improving adherence on the results of this scale $[36,37]$.

The fourth dimension of the instrument entails exercise adherence, which comprises four items. Physical activity includes all forms of exercise such as walking, cycling, active play, work-related activity, active recreation and organized sport, dancing, gardening, or playing active games. Being physically active can reduce the risk of many chronic conditions such as coronary heart disease[38]. This dimension of

Table 4 CADTAS dimensions and their Cronbach's alpha values and test-retest intraclass correlation coefficients

\begin{tabular}{lllll}
\hline CADTAS dimensions & Items & Cronbach's alpha & Intraclass correlation coefficient & $\boldsymbol{P}$ value \\
\hline Dietary adherence & $13(1-13)$ & 0.823 & 0.81 & $<0.001$ \\
Healthy lifestyle adherence & $7(14-20)$ & 0.746 & 0.83 & $>0.001$ \\
Medication adherence & $11(21-31)$ & 0.855 & 0.80 & $>0.001$ \\
Exercise adherence & $4(32-3)$ & 0.748 & 0.82 & $<0.001$ \\
Total CADTAS & $35(1-35)$ & 0.862 & 0.85 & $<0.001$ \\
\hline
\end{tabular}


CADTS has better intraclass correlation coefficient (ICC) reliability (0.82) than the Physical Activity Scale for the Elderly (PASE), which is widely used in epidemiological studies for assessing the physical activity level of the elderly (0.75) [39].

Adherence to treatment and active participation of the patient in the therapeutic process is beneficial for both individuals and communities [36]. Since studies have shown that half of the patients with chronic disease do not adhere to treatment, therefore, the assessment of patient adherence to treatment plays a vital role in the description and verification of the therapeutic process [40-42]. Due to the lack of valid and reliable tools, most previous studies assessed treatment adherence using laboratory techniques such the measurement of serum cholesterol, serum levels of mediations, and so on. However, these techniques are invasive and costly, do not provide comprehensive information about treatment adherence, and cannot be used in all healthcare settings [43]. The newly developed Medication Event Monitoring System is also very costly and just assesses medication adherence. Another pitfall of this system is its unsuitability in case of polypharmacy.

Previous studies have emphasized that there is an urgent need for studies aimed at a careful and standardized clinically applicable scale to ensure identification of patients' adherence $[36,44]$. For response to this need, we developed and have done psychometric evaluation of CADTAS. It can be completed personally by patients in around 15 min without imposing undue financial burden on them.

Due to the fact that CADTS has been developed and validated, clinicians such as physicians and nurses, can use this scale for assessment, identify related factors, and then design interventions on adherence to the treatment.

\section{Limitations}

The study was conducted in Iran. This could be a limitation to generalize the results to other regions where disease population/education and culture are different.
The test re-test reliability was done on 30 patients with 2-week interval. Short period between tests can have a memory effect. Also, reliability could have been done on a large sample.

\section{CONCLUSIONS}

CADTAS is a valid and reliable tool for the assessment of CAD patients' treatment adherence. Due to its simple scoring system, comprehensiveness, and easy applicability in different healthcare settings, CADTAS can be used by different healthcare providers, including nurses, for treatment adherence assessment among patients with CAD.

\section{ACKNOWLEDGEMENTS}

This article resulted from a PhD dissertation in Nursing approved by Tehran University of Medical Sciences, Tehran, Iran. We are thankful to the administrators of the University and the participants of the study.

Funding. No funding or sponsorship was received for this study or publication of this article.

Authorship. All named authors meet the International Committee of Medical Journal Editors (ICMJE) criteria for authorship for this article, take responsibility for the integrity of the work as a whole, and have given their approval for this version to be published.

Disclosures. Nahid Dehghan Nayeri, Mohammad Ali Yadegary, Khatereh Seylani, and Elham Navab have nothing to disclose.

Compliance with Ethics Guidelines. All procedures performed in studies involving human participants were in accordance with the Ethics Committee of the Tehran Faculty of Nursing and Midwifery with No: IR.TUMS.FNM.REC.1396.2689 and with the 1964 Helsinki Declaration and its later amendments or comparable ethical standards. 
Informed consent was obtained from all individual participants included in the study. The study setting and started sampling only after obtaining necessary approvals and permissions from the Ethics Committee of Tehran University of Medical Sciences, Tehran, Iran, and the Research Administration of Zanjan University of Medical Sciences, Zanjan, Iran. Participants were provided with obvious explanations about the aim of the study, confidential management of the study data, and perfect right of voluntary withdrawal from the study; then their consent for participation was secured.

Data Availability. The datasets during and/ or analyzed during the current study are available from the corresponding author on reasonable request.

Open Access. This article is distributed under the terms of the Creative Commons Attribution-NonCommercial 4.0 International License (http://creativecommons.org/licenses/ by-nc/4.0/), which permits any noncommercial use, distribution, and reproduction in any medium, provided you give appropriate credit to the original author(s) and the source, provide a link to the Creative Commons license, and indicate if changes were made.

\section{REFERENCES}

1. Pourghane P, Hosseini M-A, Mohammadi F, Ahmadi F, Tabari R. Patient's perception of cardiac rehabilitation after coronary artery bypass graft (CABG): a qualitative study. J Mazandaran Univ Med Sci. 2013;23(106):61-76.

2. Davarani RE, Iranpour A, Khanjani N, Mohseni M, Robati FN. Cardiovascular diseases risk factors and the relationship between knowledge level and preventive behaviors for cardiovascular diseases among women in kerman. Health Based Res. 2016;2(2):119-32.

3. Khan N, Marvel FA, Wang J, Martin SS. Digital health technologies to promote lifestyle change and adherence. Curr Treat Opt Cardiovasc Med. 2017;19(8):60.

4. Hoseinzadeh T, Paryad E, Asiri S, Leili EKN. Relationship between perception of illness and general self-efficacy in coronary artery disease patients. J Holistic Nurs Midwifery. 2012;22(1):1-8.

5. Ebadi A, Moradian T, Feizi F, Asiabi M. Comparison of hospital anxiety and depression among patients with coronary artery disease based on proposed treatment. Iran J crit Care Nurs. 2011;4:97-102.

6. Andreoli TE, Fitz JG, Benjamin I, Griggs RC, Wing EJ. Andreoli and Carpenter's Cecil essentials of medicine. E-book: Elsevier Health Sciences; 2010.

7. Allahbakhshian A, Hasankhani H, Mohammadi E, Zamanzadeh V, Ghaffari S. Second life after angioplasty: a qualitative study. Cardiovasc Nurs J. 2014;2(4):52-63.

8. Sanfélix-Gimeno G, Peiró S, Ferreros I, Pérez-Vicente R, Librero J, Catalá-López F, et al. Adherence to evidence-based therapies after acute coronary syndrome: a retrospective population-based cohort study linking hospital, outpatient, and pharmacy health information systems in Valencia, Spain. J Managed Care Pharmacy. 2013;19(3):247-57.

9. Sabaté E. Adherence to long-term therapies: evidence for action. Geneva: World Health Organization; 2003.

10. Bosworth $\mathrm{HB}$, Granger $\mathrm{BB}$, Mendys $\mathrm{P}$, Brindis R, Burkholder R, Czajkowski SM, et al. Medication adherence: a call for action. Am Heart J. 2011;162(3):412-24.

11. Park LG, Howie-Esquivel J, Chung ML, Dracup K. A text messaging intervention to promote medication adherence for patients with coronary heart disease: a randomized controlled trial. Patient Educ Couns. 2014;94(2):261-8.

12. Baljani E, Rahimi Z, Heidari S, Azimpour A. The effect of self management interventions on medication adherence and life style in cardiovascular patients. Sci J Hamadan Nurs Midwifery Faculty. 2012;20(3):58-68.

13. Negarandeh R, Mahmoodi H, Noktehdan H, Heshmat R, Shakibazadeh E. Teach back and pictorial image educational strategies on knowledge about diabetes and medication/dietary adherence among low health literate patients with type 2 diabetes. Primary Care Diabet. 2013;7(2):111-8.

14. Zakerimoghadam M, Ebrahimi S, Shahsavari $H$, Haghani H. The effect of self-management program after discharging on therapeutic adherence in patient with ischemic heart disease. Iran J Nurs Res. 2016;11(1):17-25.

15. Sanaie N, Nejati S, Zolfaghari M, Alhani F, Kazemnezhad A. The effects of family-based empowerment on family cooperation in following patient 
treatment regime after coroner arteries bypass surgery. Modern Care Sci Q Birjand Nurs Midwifery Faculty. 2014;11(1):19-27.

16. Schüz B, Marx C, Wurm S, Warner LM, Ziegelmann JP, Schwarzer R, et al. Medication beliefs predict medication adherence in older adults with multiple illnesses. J Psychosom Res. 2011;70(2):179-87.

17. Balasi LR, Paryad E, Leili EK, Booraki S, Sadeghimeibodi AM, Sheikhani NN. Study status of care adherence and its related factors in patients undergoing Coronary Artery Bypass Surgery. Holistic Nurs Midwifery J. 2015;77(25).

18. Heydari A, Ziaee E, Ebrahimzade S. The frequency Of Rehospitalization and Its Contributing Factors in Patient with Cardiovascular Diseases Hospitalized in selected Hospitals in mashhad in 2010. J Gonabad Univ Med Sci. 2011;17(3):65-72.

19. Rat A-C, Pouchot J, Guillemin F, Baumann M, RetelRude N, Spitz E, et al. Content of quality-of-life instruments is affected by item-generation methods. Int J Qual Health Care. 2007;19(6):390-8.

20. Morgado FF, Meireles JF, Neves CM, Amaral AC, Ferreira ME. Scale development: ten main limitations and recommendations to improve future research practices. Psicologia: Reflexão e Crítica. 2018;30(1):3.

21. Harrison PM, Collins T, Müllensiefen D. Applying modern psychometric techniques to melodic discrimination testing: item response theory, computerised adaptive testing, and automatic item generation. Sci Rep. 2017;7(1):3618.

22. Ten Carpenter S. Steps in scale development and reporting: a guide for researchers. Commun Methods Meas. 2018;12(1):25-44.

23. Polit DF, Beck CT. Resource manual for nursing research: generating and assessing evidence for nursing practice. Wolters Kluwer Health: Lippincott Williams \&Wilkins; 2012.

24. Juniper EF, Guyatt GH, Streiner DL, King DR. Clinical impact versus factor analysis for quality of life questionnaire construction. J Clin Epidemiol. 1997;50(3):233-8.

25. Lawshe $\mathrm{CH}$. A quantitative approach to content validity. Pers Psychol. 1975;28(4):563-75.

26. Krishna H, Kumar K. Reliability estimation in generalized inverted exponential distribution with progressively type II censored sample. J Stat Comput Simul. 2013;83(6):1007-19.
27. Knapp TR, Brown JK. Ten measurement commandments that often should be broken. Res Nurs Health. 1995;18(5):465-9.

28. Gay LR, Mills GE, Airasian PW. Educational research: competencies for analysis and applications. 10th ed. Boston: Pearson; 2012.

29. Ruscetta MN, Palmer CV, Durrant JD, Grayhack J, Ryan C. Validity, internal consistency, and test/ retest reliability of a localization disabilities and handicaps questionnaire. J Am Acad Audiol. 2005;16(8):585-95.

30. Bland JM, Altman DG. Statistics notes: Cronbach's alpha. Bmj. 1997;314(7080):572.

31. Dias A, Pereira C, Monteiro MJ, Santos C. Patients' beliefs about medicines and adherence to medication in ischemic heart disease. Aten Primaria. 2014;46:101-6.

32. Iakovleva MV. Adherence to treatment after coronary bypass surgery: psychological aspects. Revista Iberoamericana de Psicología y Salud. 2016;7(1):9-14.

33. Mertens E, Markey O, Geleijnse JM, Lovegrove JA, Givens DI. Adherence to a healthy diet in relation to cardiovascular incidence and risk markers: evidence from the Caerphilly Prospective Study. Eur J Nutr. 2018;57(3):1245-58.

34. Huijbregts P, Feskens E, Rasanen L, Fidanza F, Nissinen A, Menotti A, et al. Dietary pattern and 20 year mortality in elderly men in Finland, Italy, and The Netherlands: longitudinal cohort study. BMJ (Clin Res ed). 1997;315(7099):13-7.

35. Kim H-E, Song Y-M, Kim B-K, Park Y-S, Kim M-H. Factors associated with persistent smoking after the diagnosis of cardiovascular disease. Korean J Family Med. 2013;34(3):160.

36. Kubica A, Kosobucka A, Michalski P, Fabiszak T, Felsmann M. Self-reported questionnaires for assessment adherence to treatment in patients with cardiovascular diseases. Med ResJ. 2017;2(4):115-22.

37. Unni EJ, Farris KB. Development of a new scale to measure self-reported medication nonadherence. Res Soc Adm Pharmacy. 2015;11(3):e133-43.

38. Pavey T, Taylor A, Fox K, Hillsdon M, Anokye N, Campbell J, et al. Effect of exercise referral schemes in primary care on physical activity and improving health outcomes: systematic review and metaanalysis. BMJ (Clin Res ed). 2011;343:d6462.

39. Ngai SP, Cheung RT, Lam PL, Chiu JK, Fung EY. Validation and reliability of the physical activity 
scale for the elderly in Chinese population. J Rehabil Med. 2012;44(5):462-5.

40. Marcum ZA, Zheng Y, Perera S, Strotmeyer E, Newman AB, Simonsick EM, et al. Prevalence and correlates of self-reported medication non-adherence among older adults with coronary heart disease, diabetes mellitus, and/or hypertension. Res Soc Adm Pharmacy. 2013;9(6):817-27.

41. Kripalani S, Schmotzer B, Jacobson TA. Improving medication adherence through graphically enhanced interventions in coronary heart disease (IMAGE-CHD): a randomized controlled trial. J Gen Intern Med. 2012;27(12):1609-17.
42. Tang L, Patao C, Chuang J, Wong ND. Cardiovascular risk factor control and adherence to recommended lifestyle and medical therapies in persons with coronary heart disease (from the National Health and Nutrition Examination Survey 2007-2010). Am J Cardiol. 2013;112(8):1126-32.

43. Vulic D, Loncar S, Krneta M, Skrbic R, Lazarevic A, Lee BT, et al. Risk factor control and adherence to treatment in patients with coronary heart disease in the Republic of Srpska, Bosnia and Herzegovina in 2005-2006. Arch Med Sci AMS. 2010;6(2):183.

44. Ho PM, Bryson CL, Rumsfeld JS. Medication adherence: its importance in cardiovascular outcomes. Circulation. 2009;119(23):3028-35. 